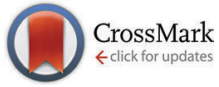

Cite this: Chem. Commun., 2016, 52,3054

Received 24th August 2015, Accepted 11th January 2016

DOI: $10.1039 / \mathrm{c} 5 \mathrm{cc} 07107 \mathrm{k}$

www.rsc.org/chemcomm

\section{One-step ligand exchange and switching from hydrophobic to water-stable hydrophilic superparamagnetic iron oxide nanoparticles by mechanochemical milling $\dagger$}

\author{
Katalin V. Korpany, ${ }^{a}$ Cristina Mottillo, ${ }^{a}$ Jill Bachelder, ${ }^{a}$ Shoronia N. Cross, ${ }^{a}$ \\ Pengcheng Dong, ${ }^{b}$ Simon Trudel, ${ }^{b}$ Tomislav Friščić ${ }^{a}$ and \\ Amy Szuchmacher Blum*a
}

\begin{abstract}
We describe a simple, rapid methodology for the synthesis of water-stable iron oxide nanoparticles (IONPs) compatible with a variety of aqueous buffers, based on mechanochemical milling exchange of covalently bound surface ligands on pre-fabricated oleic acid-protected IONPs. Application of milling for IONP ligand exchange eliminates steps required for transforming hydrophobic into negatively charged, water-soluble superparamagnetic IONPs.
\end{abstract}

Water-stable superparamagnetic iron oxide nanoparticles (IONPs) ${ }^{1,2}$ are rapidly developing into a system of choice for diverse applications in materials and life sciences, including catalysis, ${ }^{3}$ magnetic fluids, ${ }^{4}$ data storage, ${ }^{5,6}$ biomedicine, and magnetic resonance imaging (MRI). ${ }^{7}$ However, the development of IONP-based systems and applications is hindered by the synthetic challenge of preparing nanoparticles in the size range 5-20 $\mathrm{nm}$ that are monodisperse, compatible with and stable in water-containing environments, such as those found in biological systems, and yield a strong enough magnetic response. ${ }^{8}$ Most conventional procedures for generating monodisperse IONPs use highly hydrophobic oleic acid ligands, incompatible with aqueous environments, and most procedures for generating water-soluble IONPs are synthetically demanding, requiring specially-designed watercompatible ligands. ${ }^{1,9-11} \ddagger$ Consequently, the development of simple methods to generate IONPs stable in aqueous environments remains the subject of vigorous inquiry. ${ }^{12}$ We have recently described a strategy to generate superparamagnetic, water-soluble IONPs from oleic acid-substituted precursor nanoparticles (1) by multi-step exchange of oleic acid ligands with highly polar,

\footnotetext{
${ }^{a}$ Department of Chemistry, McGill University, 801 Sherbrooke St. W., H3A oB8 Montreal, Canada.E-mail: amy.blum@mcgill.ca, tomislav.friscic@mcgill.ca; Tel: +1-514-398-3959

${ }^{b}$ Department of Chemistry, Centre for Advanced Solar Materials, and Institute for Quantum Science and Technology, University of Calgary, 2500 University Drive N.W., Calgary, AB T2N 1N4, Canada

$\dagger$ Electronic supplementary information (ESI) available: Details of solution syntheses, instrumental analysis, particle size distributions, TEM images, and PXRD patterns. See DOI: 10.1039/c5cc07107k
}

commercially accessible Tiron (4,5-dihydroxy-1,3-benzenedisulfonic acid disodium salt monohydrate, Scheme 1). ${ }^{13}$ However, while using pre-fabricated $\mathbf{1}$ ensured product monodispersity, it complicates ligand exchange due to solvent incompatibility between the hydrophobic precursor IONPs and ionic Tiron. Replacing oleic acid ligands with Tiron requires an intermediate substitution step involving dopamine (Scheme 1a), a molecule compatible with a variety of polar and non-polar environments. The exchange yields oleic acid- and dopaminesubstituted IONPs that are converted into water-soluble IONPs stabilized with both Tiron and residual dopamine in a second ligand exchange step. This process reveals solvent incompatibility as the principal obstacle in developing a simple and rapid procedure for converting $\mathbf{1}$ into water-stable superparamagnetic IONPs.

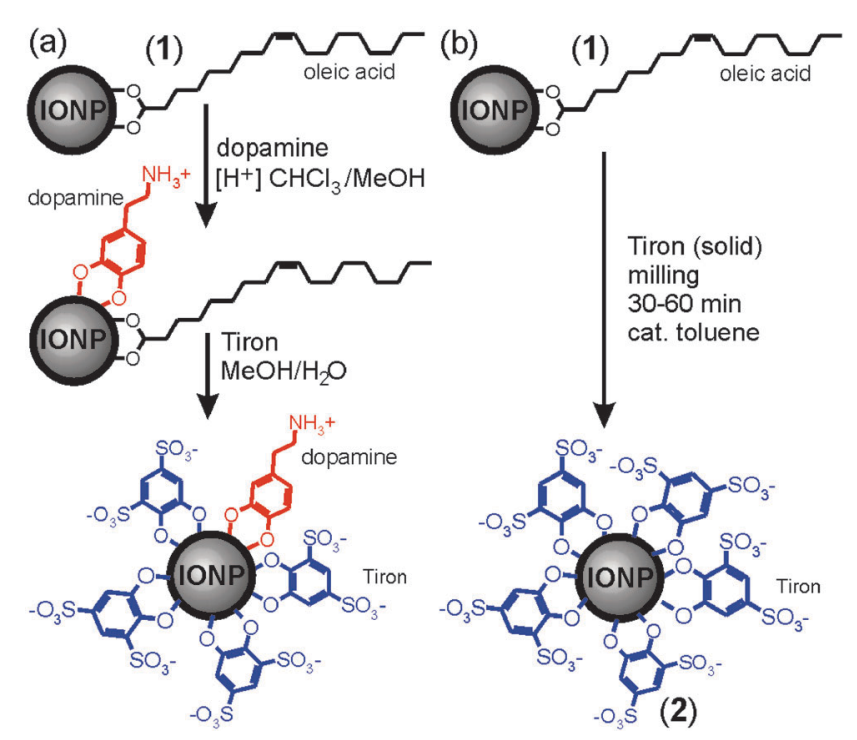

Scheme 1 Synthesis of water-soluble IONPs by: (a) two-step ligand exchange in solution, leading to exchange of oleic acid ligands ${ }^{13}$ and (b) herein demonstrated one-step mechanochemical solvent-free process. 
A possible means to circumvent solvent compatibility limitations is mechanochemistry, i.e. reactivity by milling, grinding, or shearing. ${ }^{14}$ Milling has long been known as a method of top-down particle comminution, especially for binary inorganic compounds and metals, giving particles in size ranging from 20 to $50 \mathrm{~nm}^{15}$ Recently, it also became clear that mechanochemical milling can afford monodisperse nanoparticles of inorganic sulfides, oxides, or metals through a bottom-up synthesis approach. ${ }^{16}$ However, neither of these milling approaches yields oxide nanoparticles in the ultrasmall size range $(1-10 \mathrm{~nm})$ desired for many applications, especially biomedicine, where smaller particles have much longer circulation times and exhibit pronounced superparamagnetic behavior. ${ }^{17}$

We now demonstrate a mechanochemical milling strategy for the rapid and direct replacement of oleate ligands on prefabricated $5 \mathrm{~nm}$ diameter IONPs with Tiron, retaining their size, shape, and superparamagnetic properties. The procedure eliminates the need for intermediate substitution steps in making superparamagnetic dopamine-free IONPs (2) soluble in aqueous buffers, thus effectively switching from hydrophobic to water-compatible IONPs in one simple step. To the best of our knowledge, this is also the first application of mechanochemistry for exchange of covalently bound surface ligands on nanoparticles whose size permits superparamagnetism and biomedical applications.

The synthesis of initial oleic acid-substituted IONPs was performed via a conventional procedure, ${ }^{13}$ affording highly monodisperse 1 with sizes close to $5 \mathrm{~nm}$, as established by transmission electron microscopy (TEM). Mechanochemical ligand exchange was performed on a scale usual in laboratory IONP synthesis, by milling $5 \mathrm{mg}$ of 1 with excess solid Tiron (25 to $100 \mathrm{mg}$ ). Initial attempts of ligand exchange were disappointing, as subsequent attempts to re-suspend the IONPs in aqueous solution were only partially successful. Furthermore, in the absence of solvent, 60 minutes of grinding was required to generate hydrophilic IONPs. Next, we explored liquid-assisted grinding (LAG), ${ }^{18}$ a mechanochemical milling technique that utilizes a catalytic amount of a liquid phase to accelerate or direct mechanochemical processes. The liquid enables modification of the course of mechanochemical reactions, while avoiding problems of solvolysis or solubility. ${ }^{19}$ LAG was conducted by adding $10 \mu \mathrm{L}$ of toluene $(94 \mu \mathrm{mol})$ to the reaction mixture, corresponding to the ratio of liquid volume to mass of solid sample $\eta=0.10 \mu \mathrm{L} \mathrm{mg}^{-1} \cdot{ }^{19}$ After $30 \mathrm{~min}$ milling, the product was soluble in water without residue, consistent with the formation of 2.

Surface modification was confirmed by Fourier transform infrared attenuated total reflectance (FTIR-ATR) spectroscopy of IONPs before and after LAG (60 min mill time). The spectra reveal almost complete disappearance of oleic acid bands (e.g. $\mathrm{CH}_{2}$ stretches at $2800-3000 \mathrm{~cm}^{-1}$ and $\mathrm{COO}^{-}$stretches at $1520 \mathrm{~cm}^{-1}$ and $1448 \mathrm{~cm}^{-1}$ ) upon LAG (Fig. 1a). At the same time, samples after LAG exhibited absorption bands characteristic of adsorbed Tiron (Fig. 1b), consistent with the efficient replacement of surface oleic acid with Tiron. The sample remained in the form of monodisperse nanoparticles, as demonstrated by TEM
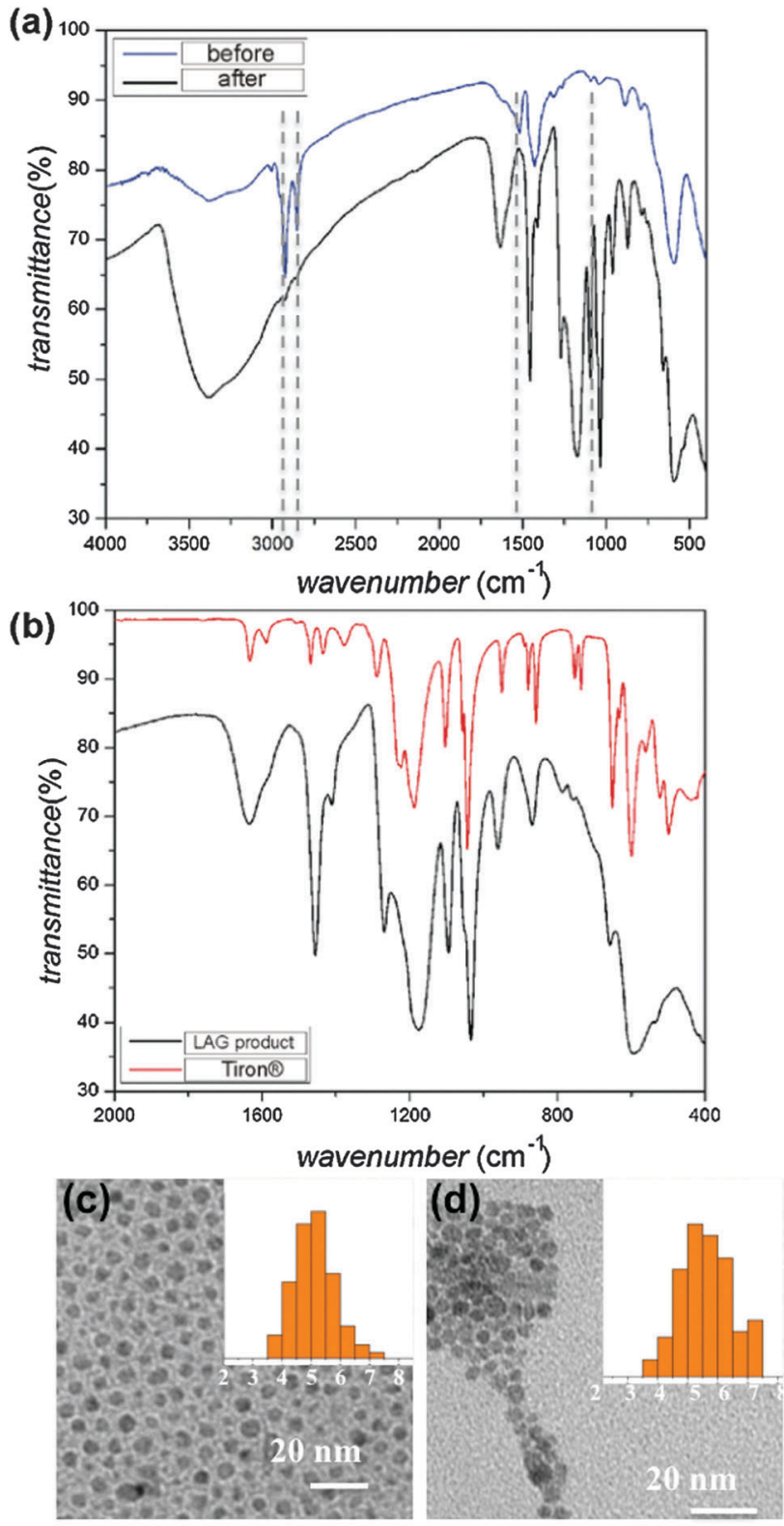

Fig. 1 Comparison of FTIR-ATR spectra for: (a) precursor IONPs 1 before (blue) and after (black) LAG with Tiron (100 mg Tiron, $10 \mu \mathrm{L}$ toluene), demonstrating the almost complete disappearance of characteristic oleic acid absorption bands namely $\mathrm{CH}_{2}$ stretches at $2800-3000 \mathrm{~cm}^{-1}$ and $\mathrm{COO}^{-}$stretches at $1520 \mathrm{~cm}^{-1}$ and $1448 \mathrm{~cm}^{-1}$. Dashed lines are guides for the eye; (b) Tiron reactant and product of LAG of 1 and Tiron $(100 \mathrm{mg}$ Tiron, $10 \mu \mathrm{L}$ toluene). Spectra in (a) and (b) confirm the mechanochemical replacement of surface oleic acid on 1 with Tiron. Comparison of TEM images for 1: (c) before and (d) after LAG with Tiron, demonstrating the retention of nanoparticle size and low size dispersity. Insets show size distribution (see also ESI, $\dagger$ Fig. S5).

analysis of particles before (diameter: $5.1 \pm 0.7 \mathrm{~nm}$ ) and after (diameter: $5.6 \pm 0.8 \mathrm{~nm}$ ) LAG (Fig. 1c, and d). $\S$

To quantify the extent of IONP surface derivatization and their stability in aqueous environments, we measured the $\zeta$-potential of particles ${ }^{20-22}$ prepared by LAG dispersed in $\mathrm{pH} 7.00$ (20 mM) sodium phosphate buffer (Table 1). The highly negative potential $(-53.86 \pm 2.62 \mathrm{mV})$ is consistent with extensive 
Table 1 Characterization of $\mathbf{2}$ under different LAG conditions ${ }^{a, b, c}$

\begin{tabular}{|c|c|c|c|}
\hline $\begin{array}{l}m \text { (Tiron) } \\
\text { (mg) }\end{array}$ & $\begin{array}{l}\zeta \text {-Potential } \\
(\mathrm{mV})\end{array}$ & $\begin{array}{l}\text { Mobility } \\
\left(10^{-8} \mathrm{~m}^{2} \mathrm{~s}^{-1} \mathrm{v}^{-1}\right)\end{array}$ & $\begin{array}{l}c(\mathrm{Fe}) \\
\left(\mathrm{mg} \mathrm{mL}^{-1}\right)\end{array}$ \\
\hline 100 & $-53.86 \pm 2.62$ & $-4.17 \pm 0.20$ & 0.314 \\
\hline 100 & $-50.40 \pm 2.57$ & $-3.94 \pm 0.20$ & 0.341 \\
\hline 100 (DMF) & $-36.14 \pm 1.02$ & $-2.82 \pm 0.08$ & 0.361 \\
\hline 100 (neat) & $-49.07 \pm 1.62$ & $-3.83 \pm 0.13$ & 0.398 \\
\hline 75 & $-47.29 \pm 1.56$ & $-3.69 \pm \mathbf{0 . 1 2}$ & 0.452 \\
\hline 75 & $-51.11 \pm 0.70$ & $-3.99 \pm 0.05$ & 0.323 \\
\hline 50 & $-40.08 \pm 3.52$ & $-3.13 \pm 0.27$ & 0.104 \\
\hline 50 & $-46.76 \pm 2.53$ & $-3.65 \pm 0.20$ & 0.148 \\
\hline 50 & $-47.96 \pm 0.92$ & $-3.75 \pm 0.07$ & 0.396 \\
\hline 25 & $-33.29 \pm 2.72$ & $-2.60 \pm 0.21$ & 0.446 \\
\hline 25 & $-38.93 \pm 2.56$ & $-3.04 \pm 0.20$ & 0.242 \\
\hline
\end{tabular}

replacement of oleic acid with Tiron and resulting high aqueous stability. ${ }^{23}$ Indeed, this $\zeta$-potential exceeds that measured for nanoparticles obtained by two-step ligand exchange in solution $(-40 \mathrm{mV}),{ }^{13}$ indicating that mechanochemistry affords IONPs with the high $\zeta$-potentials associated with enhanced aqueous stability. We explored the $\zeta$-potential of particles obtained under different milling conditions (Table 1 ). ${ }^{24}$ Toluene appears important for successful exchange, as switching to a different liquid additive (e.g. $N, N$-dimethylformamide, DMF) gave much less negatively charged particles. In the absence of toluene, the minimum required milling time for successful ligand replacement doubled.

Varying the milling time from 30 to $60 \mathrm{~min}$ had little effect on $\zeta$-potential, as did reducing the amount of Tiron down to $50 \mathrm{mg}$. The magnitude of the $\zeta$-potential of the LAG product sank below $-40 \mathrm{mV}$ only upon reducing the amount of Tiron to $25 \mathrm{mg}$ (Table 1). These results suggest that excess Tiron is important for successful ligand exchange on IONP surface. This may be due to excess Tiron acting as a diluent, hindering IONP growth, or as a soft material that buffers the impact of milling media and therefore mechanical damage to IONPs. ${ }^{25}$ TEM analysis looking at the impact of the amount of Tiron present during milling on the nanoparticle size shows that there is no significant change in size after $60 \mathrm{~min}$ milling in the presence of $25 \mathrm{mg}$ Tiron (ESI, $\dagger$ Fig. S6, mean diameter $5.1 \pm 0.8 \mathrm{~nm}$ ). In the presence of $100 \mathrm{mg}$ Tiron, there is a small shift in the mean particle size (mean diameter $5.6 \pm 0.8 \mathrm{~nm}$ ), but this shift is within the error range of the measurement. Tiron-stabilized IONPs were soluble in a wide range of aqueous solutions: $20 \mathrm{mM}$ sodium acetate ( $\mathrm{pH} 5.00)$, DI water, $20 \mathrm{mM}$ sodium phosphate ( $\mathrm{pH} 7.19$ ), and $0.2 \mathrm{M}$ Tris (pH 9.26). Aqueous IONP solutions stored at room temperature showed no visible precipitate after 11 weeks, demonstrating the stability of the particles over time. In addition, IONPs were partially soluble in $S, S$-dimethylsufoxide (DMSO) and partially-mostly soluble in DMF.

Superconducting quantum interference device (SQUID) magnetometry measurements were performed to evaluate IONP magnetic properties before and after milling. Both $\mathbf{1}$ and $\mathbf{2}$ are clearly superparamagnetic, exhibiting magnetic hysteresis only at low temperatures (Fig. 2a and b) and demonstrating typical
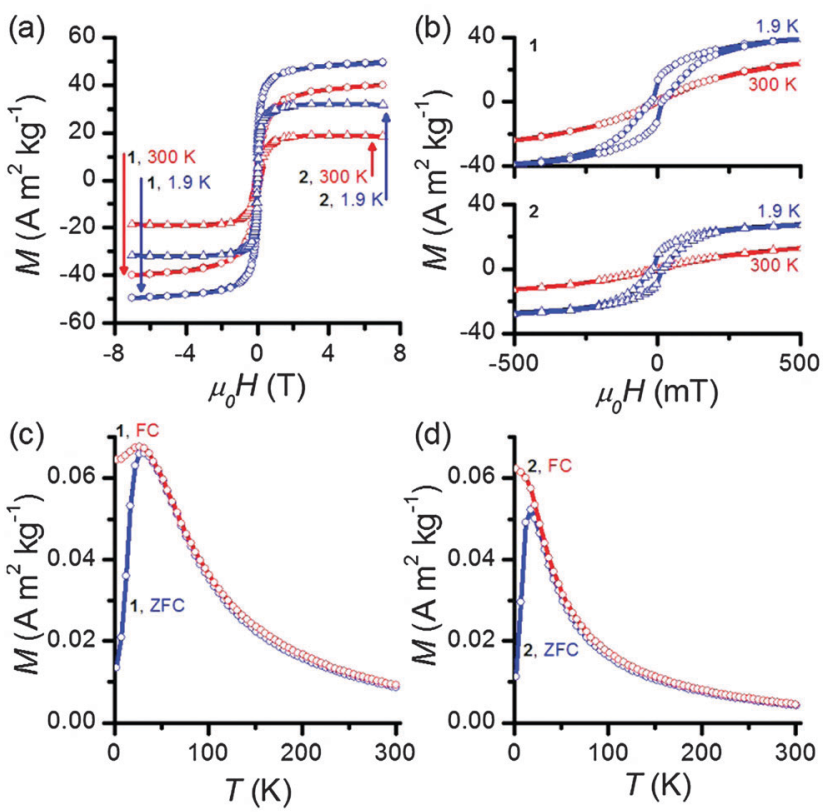

Fig. 2 Magnetic properties of $\mathbf{1}$ and 2. (a) $M$ vs. $H$ loops to $7 \mathrm{~T}$ at 1.9 and $300 \mathrm{~K}$, (b) showing the low-field region and the emergence of hysteresis at low temperature for both $\mathbf{1}$ and $\mathbf{2}$. (c and d) Field-cooled (FC) and zerofield-cooled (ZFC) measurements showing temperature-dependent magnetization under $10 \mathrm{mT}$. For 1 , the blocking temperature $\left(T_{\mathrm{B}}\right)$ is $32 \mathrm{~K}$, indicated by the peak of the ZFC curve (c), and for $\mathbf{2}(\mathrm{d}) T_{\mathrm{B}}=17 \mathrm{~K}$. Based on the shape of the FC-ZFC plots, the particle size distribution of both 1 and 2 appears narrow.

temperature-dependent behavior (Fig. 2c and d). The blocking temperature $T_{\mathrm{B}}$, as determined by the convergence of the FC/ZFC curves is $32 \mathrm{~K}$ for IONP-OA and $17 \mathrm{~K}$ for IONP-Tiron. These blocking temperatures are consistent with previous results. ${ }^{13}$ The magnetic response of superparamagnetic nanoparticles above the blocking temperature is described by $M(H)=$ $M_{\mathrm{S}} L(x)$, where $L(x)$ is the Langevin function and $x=\mu \nu H / k_{\mathrm{B}} T .^{26}$ Fitting to this expression affords $\nu$, the volume of nanoparticles assumed to be monodisperse spheres, using the saturation magnetization $M_{\mathrm{s}}$ determined experimentally from the isothermal $M(H)$ loops (Fig. 2a), assuming the bulk volume magnetization of $\mathrm{Fe}_{3} \mathrm{O}_{4}\left(\mu=4.8 \times 105 \mathrm{~A} \mathrm{~m}^{-1}\right) .{ }^{27}$ This model suggests a magnetic size of 4.68(2) $\mathrm{nm}$ for oleic-acid-substituted IONPs, and a magnetic size of 4.64(1) $\mathrm{nm}$ for Tiron-substituted ones, consistent with TEM measurements showing particles close to $5 \mathrm{~nm}$ in diameter with a thin surface magnetically disordered region. ${ }^{28}$ Importantly, this shows that the IONPs remain superparamagnetic after the ligand exchange protocol.

In summary, we have demonstrated a mechanochemical approach to exchange the covalently bound ligand shell of IONPs in a single step, with the retention of nanoparticle superparamagnetic properties, small size and monodispersity. Using this method, we achieved the first one-step conversion of monodisperse hydrophobic oleic-acid capped superparamagnetic IONPs to hydrophilic Tiron-capped IONPs. By using milling, we avoid problems of solvent incompatibility, reduce the total amount of solvent required, and completely eliminate 
the need for chlorinated solvents. The required power consumption per experiment performed in a mill operating at $30 \mathrm{~Hz}$ is about $30 \mathrm{~W}$, i.e. comparable to that of a lightbulb. We are currently investigating the generality of this simple mechanochemical approach for generating diversely-functionalized superparamagnetic IONPs.

We acknowledge financial support from the Centre for SelfAssembled Chemical Structures (CSACS), the Centre for Green Chemistry and Catalysis (CCVC), NSERC Discovery Grant program, and the Canada Foundation for Innovation. We thank Dorothy Majewski (zeta potential) and Joshua Lucate (TEM) for assistance with experiments. CM acknowledges the support of the Sigma Xi Grant-in-Aid-of-Research (GIAR) and the FRQNT predoctoral scholarship.

\section{Notes and references}

\$ A notable exception is the use of the continuous flow spinning disc processing technique that can achieve synthesis of $5-10 \mathrm{~nm}$ superparamagnetic $\mathrm{Fe}_{3} \mathrm{O}_{4}$ nanoparticles in the absence of oleic acid. ${ }^{10}$

$\S$ The IONPs could not be characterised by dynamic light scattering (DLS), possibly due to their small size, which is at the limit of our instrument. However, this observation suggests that the IONPs do not aggregate in aqueous solution.

1 E. Amstad, T. Gillich, I. Bilecka, M. Textor and E. Reimhult, Nano Lett., 2009, 9, 4042.

2 G. M. da Costa, C. Blanco-Andujar, E. De Grave and Q. A. Pankhurst, J. Phys. Chem. B, 2014, 118, 11738.

3 R. Hudson, Y. T. Feng, R. S. Varma and A. Moores, Green Chem., 2014, 16, 4493.

4 M. D. Shultz, J. U. Reveles, S. N. Khanna and E. E. Carpenter, J. Am. Chem. Soc., 2007, 129, 2482.

5 S. Lee, A. Fursina, J. T. Mayo, C. T. Yavuz, V. L. Colvin, R. G. S. Sofin, I. V. Shvets and D. Natelson, Nat. Mater., 2008, 7, 130.

6 M. Uenuma, T. Ban, N. Okamoto, B. Zheng, Y. Kakihara, M. Horita, Y. Ishikawa, I. Yamashita and Y. Uraoka, RSC Adv., 2013, 3, 18044.

7 (a) A. K. Gupta and M. Gupta, Biomaterials, 2005, 26, 3995; (b) S. Laurent, S. Dutz, U. O. Hafeli and M. Mahmoudi, Adv. Colloid Interface Sci., 2011, 166, 8; (c) L. Li, W. Jiang, K. Luo, H. M. Song, F. Lan, Y. Wu and Z. W. Gu, Theranostics, 2013, 3, 595.

8 D. Caruntu, G. Caruntu and C. J. O'Connor, J. Phys. D: Appl. Phys., 2007, 40, 5801.

9 A. H. Lu, E. L. Salabas and F. Schuth, Angew. Chem., Int. Ed., 2007, 46, 1222 .

10 (a) S. F. Chin, K. S. Iyer, C. L. Raston and M. Saunders, Adv. Funct. Mater., 2008, 18, 922; (b) C. L. Tong, E. Eroglu and C. L. Raston, RSC Adv., 2014, 4, 46718.

11 A. K. L. Yuen, G. A. Hutton, A. F. Masters and T. Maschmeyer, Dalton Trans., 2012, 41, 2545.

12 (a) H. O. Qu, D. Caruntu, H. X. Liu and C. J. O'Connor, Langmuir, 2011, 27, 2271; (b) G. K. Wang, S. Inturi, N. J. Serkova, S. Merkulov, K. McCrae, S. E. Russek and N. K. Banda, ACS Nano, 2014, 8, 12437; (c) H. Wei, N. Insin, J. Lee, H. S. Han, J. M. Cordero, W. H. Liu and M. G. Bawendi, Nano Lett., 2012, 12, 22.
13 K. V. Korpany, F. Habib, M. Murugesu and A. S. Blum, Mater. Chem. Phys., 2013, 138, 29.

14 (a) S. L. James, C. J. Adams, C. Bolm, D. Braga, P. Collier, T. Friščić, F. Grepioni, K. D. M. Harris, G. Hyett, W. Jones, A. Krebs, J. Mack, L. Maini, A. G. Orpen, I. P. Parkin, W. C. Shearouse, J. W. Steed and D. C. Waddell, Chem. Soc. Rev., 2012, 41, 413; (b) A. Bruckmann, A. Kreb and C. Bolm, Green Chem., 2008, 10, 1131; (c) A. Stolle, T. Szuppa, S. E. S. Leonhardt and B. Ondruschka, Chem. Soc. Rev., 2011, 40, 2317; (d) K. Vimalanathan, X. J. Chen and C. L. Raston, Chem. Commun., 2014, 50, 11295; (e) R. B. N. Baig and R. S. Varma, Chem. Soc. Rev., 2012, 41, 1559; $(f)$ E. Boldyreva, Chem. Soc. Rev., 2013, 42, 7719; (g) D. Braga, L. Maini and F. Grepioni, Chem. Soc. Rev., 2013, 42, 7638.

15 (a) C. Xu, S. De, A. M. Balu, M. Ojeda and R. Luque, Chem. Commun., 2015, 51, 6698; (b) P. Baláž, M. Achimovičová, M. Baláž, P. Billik, Z. Cherkezova-Zheleva, J. M. Criado, F. Delogu, E. Dutková, E. Gaffet, F. J. Gotor, R. Kumar, I. Mitov, T. Rojac, M. Senna, A. Streletskii and K. Wieczorek-Ciurowa, Chem. Soc. Rev., 2013, 42, 7571; (c) C. Suryanarayana, Prog. Mater. Sci., 2001, 46, 1; (d) I. M. Joni, R. Balgis, T. Ogi, T. Iwaki and K. Okuyama, Colloids Surf., A, 2011, 388, 49; (e) V. Šepelák, S. Bégin-Colin and G. Le Caër, Dalton Trans., 2012, 41, 11927; $(f)$ V. Šepelák, A. Düvel, M. Wilkening K.-D. Becker and P. Heitjans, Chem. Soc. Rev., 2013, 42, 7507; $(g)$ J. Huot, M.-L. Tremblay and R. Schulz, J. Alloys Compd., 2003, 356-357, 603; (h) K. L. Da Silva, D. Menzel, A. Feldhoff, C. Kübel, M. Bruns, A. Paesano Jr., A. Düvel, M. Wilkening, M. Ghafari, H. Hahn, F. J. Litterst, P. Heitjans, K. D. Becker and V. Sepelák, J. Phys. Chem. C, 2011, 115, 7209; (i) V. Šepelák, I. Bergmann, S. Indris, A. Feldhoff, H. Hahn, K. D. Becker, C. P. Grey and P. Heitjans, J. Mater. Chem., 2011, 21, 8332.

16 (a) M. Baláž, P. Baláž, G. Tjuliev, A. Zubrík, M. J. Sayagués, A. Zorkovská and N. Kostova, J. Mater. Sci., 2013, 48, 2424; (b) P. Baláž, M. Baláž, M. Čaplovičová, A. Zorkovská, L. Čaplovič and M. Psotka, Faraday Discuss., 2014, 170, 169; (c) M. Ojeda, A. Pineda, A. A. Romero, V. Barron and R. Luque, ChemSusChem, 2014, 7, 1876; (d) M. J. Rak, N. K. Saade, T. Friščić and A. Moores, Green Chem., 2014, 16, 86.

17 S. Mornet, S. Vasseur, F. Grasset and E. Duguet, J. Mater. Chem., 2004, 14, 2161.

18 (a) G. A. Bowmaker, Chem. Commun., 2013, 49, 334; (b) D. Braga, S. L. Giaffreda, F. Grepioni, A. Pettersen, L. Maini, M. Curzi and M. Polito, Dalton Trans., 2006, 1249; (c) T. Friščić, Chem. Soc. Rev., 2012, 41, 3493.

19 T. Friščić, S. L. Childs, S. A. A. Rizvi and W. Jones, CrystEngComm, 2009, 11, 418.

20 D. Hanaor, M. Michelazzi, C. Leonelli and C. C. Sorrell, J. Eur. Ceram. Soc., 2012, 32, 235.

21 M. von Smoluchowski, Bull. Int. Acad. Sci. Cracovie, 1903, 184.

22 M. Di Marco, I. Guilbert, M. Port, C. Robic, P. Couvreur and C. Dubernet, Int. J. Pharm., 2007, 331, 197.

23 K. Suttiponparnit, J. K. Jiang, M. Sahu, S. Suvachittanont, T. Charinpanitkul and P. Biswas, Nanoscale Res. Lett., 2011, 6, 27.

24 A. Stolle, R. Schmidt and K. Jacob, Faraday Discuss., 2014, 170, 267.

25 J.-L. Do, C. Mottillo, D. Tan, V. Štrukil and T. Friščić, J. Am. Chem. Soc., 2015, 137, 2476.

26 (a) L. Néel, Ann. Geophys., 1949, 5, 99; (b) S. Trudel, C. H. W. Jones and R. H. Hill, J. Mater. Chem., 2007, 17, 2206.

27 J. Orna, P. A. Algarabel, L. Morellon, J. A. Pardo, J. M. de Teresa, R. L. Anton, F. Bartolome, L. M. Garcia, J. Bartolome, J. C. Cezar and A. Wildes, Phys. Rev. B: Condens. Matter Mater. Phys., 2010, 81, 144420.

28 J. Cheon and J. H. Lee, Acc. Chem. Res., 2008, 41, 1630. 